\title{
Do plant-based biogeographical regions shape aphyllophoroid fungal communities in Europe?
}

\section{Ordynets, Alexander}

2018-05

Ordynets , A , Heilmann-Clausen , J Savchenko , A, Baessler , C , Volobuev , S , Akulov , O , Karadelev , M , Kotiranta , H , Saitta , A , Langer , E \& Abrego , N 2018 , ' Do plant-based biogeographical regions shape aphyllophoroid fungal communities in Europe? ' , Journal of Biogeography, vol. 45 , no. 5 , pp. 1182-1195 . https://doi.org/10.1111/jbi.13203

http://hdl.handle.net/10138/307608

https://doi.org/10.1111/jbi.13203

publishedVersion

Downloaded from Helda, University of Helsinki institutional repository.

This is an electronic reprint of the original article.

This reprint may differ from the original in pagination and typographic detail.

Please cite the original version. 


\title{
Do plant-based biogeographical regions shape aphyllophoroid fungal communities in Europe?
}

\author{
Alexander Ordynets $^{1}$ (D) | Jacob Heilmann-Clausen ${ }^{2}$ | Anton Savchenko $^{3}$ | \\ Claus Bässler $^{4,5}$ | Sergey Volobuev ${ }^{6}$ | Olexander Akulov ${ }^{7}$ | Mitko Karadelev ${ }^{8}$ | \\ Heikki Kotiranta $^{9}$ | Alessandro Saitta ${ }^{10}$ | Ewald Langer $^{1}$ | Nerea Abrego ${ }^{11,12}$
}

\footnotetext{
${ }^{1}$ Department of Ecology, FB10 Mathematics and Natural Sciences, University of Kassel, Kassel, Germany

${ }^{2}$ Centre for Macroecology, Evolution and Climate, Natural History Museum of Denmark, University of Copenhagen, Copenhagen, Denmark

${ }^{3}$ Institute of Ecology and Earth Sciences, University of Tartu, Tartu, Estonia

${ }^{4}$ Bavarian Forest National Park, Mycology and Climatology Section Research, Grafenau, Germany

${ }^{5}$ Department of Ecology and Ecosystem Management, Chair of Terrestrial Ecology, Technical University of Munich, Freising, Germany

${ }^{6}$ Laboratory of Systematics and Geography of Fungi, Komarov Botanical Institute, Russian Academy of Sciences, St. Petersburg, Russia

${ }^{7}$ Department of Mycology and Plant Resistance, VN Karazin Kharkiv National University, Kharkiv, Ukraine

${ }^{8}$ Faculty of Natural Sciences and Mathematics, Institute of Biology, Ss Cyril and Methodius University, Skopje, Macedonia

${ }^{9}$ Finnish Environment Institute, Helsinki, Finland

${ }^{10}$ Department of Agricultural, Food and Forest Sciences, Università di Palermo, Palermo, Italy

${ }^{11}$ Department of Biology, Centre for Biodiversity Dynamics, Norwegian University of Science and Technology, Trondheim, Norway

${ }^{12}$ Department of Agricultural Sciences, University of Helsinki, Helsinki, Finland
}

\section{Correspondence}

Alexander Ordynets, Department of Ecology, FB10 Mathematics and Natural Sciences, University of Kassel, Kassel, Germany. Email: a.ordynets@uni-kassel.de

\section{Funding information}

Danmarks Grundforskningsfond, Grant/ Award Number: DNRF96; Norges Forskningsråd, Grant/Award Number: CoE grant no. 223257; Grant of the President of Russian Federation, Grant/Award Number: MK-6345.2015.4; Hessisches Ministerium für Wissenschaft und Kunst, Grant/Award Number: LOEWE Schwerpunkt für Integrative Pilzforschung; Aage V. Jensen Naturfond

Editor: Alain Vanderpoorten

\begin{abstract}
Aim: Aphyllophoroid fungi are associated with plants, either using plants as a resource (as parasites or decomposers) or as symbionts (as mycorrhizal partners). In spite of their strong association with plants, it is unknown how much plant distributions determine their biogeographical patterns compared with environmental factors such as climate and human land use. In this study, our aims are to (1) describe the spatial diversity patterns of aphyllophoroid fungi in Europe and (2) identify the factors shaping these patterns.

Location: Europe, as well as the adjacent Subarctic to Arctic islands (Greenland, Faroe Islands, Iceland, Svalbard), Palestine and the south-east coast of the Caspian Sea.

Methods: We compiled a dataset consisting of 14,030 fruitbody occurrences of 1,491 aphyllophoroid fungal species from 39 geographical areas (17 countries) belonging to eight biogeographical regions. We assessed the differences in fungal species richness and overall diversity and its nestedness and turnover components across biogeographical regions of Europe, as well as between southern and northern Europe (based on geographical latitude of $50^{\circ}$ as threshold). We used cluster and ordination analyses to classify the European aphyllophoroid communities biogeographically and evaluated the importance of climate, host-tree species, topography and human land-use intensity in explaining biogeographical variation.
\end{abstract}


Results: The importance of biogeographical regions in determining European aphyllophoroid fungal communities varies for different diversity components. Species richness and nestedness are best explained by plant-based biogeographical regions, whereas overall beta diversity and species turnover are driven mostly by variation in climate, and nestedness mostly by tree species occupancy. Beta-diversity patterns of aphyllophoroid fungi do not differ between southern and northern Europe.

Main conclusions: At the continental scale, aphyllophoroid fungi are less shaped by historical legacies than vascular plant and animal communities, and trends of overall beta diversity in southern and northern Europe are similar to patterns found for bryophytes.

\section{KEYWORDS}

beta diversity, community dissimilarity, macrofungi, nestedness, north, south, species richness, species turnover

\section{INTRODUCTION}

Understanding the variation in global distribution patterns of species has fascinated researchers for over two centuries (von Humboldt \& Bonpland, 1805; Wallace, 1876), and the classification of species pools into geographical units, that is, biogeographical regions, is a classic scientific discipline (Cox, Moore, \& Ladle, 2016). Traditionally, the delineation of biogeographical units relied on taxonomic opinions about endemic taxa (Takhtajan, 1978; Wallace, 1876), whereas modern biogeographical classifications are based on replicable and quantitative techniques. Current multivariate methods enable a more systematic understanding of the current and past distribution patterns of species worldwide (Holt et al., 2013; Kreft \& Jetz, 2010; Linder et al., 2012) and provide important input for detecting areas requiring special attention for biodiversity conservation (Whittaker et al., 2005). The spatial classification of species communities also enables the exploration of evolutionary history shaping biodiversity on earth, including the structure of food webs (Dyer et al., 2007; Nieberding \& Olivieri, 2007).

Compared with plants and vertebrates, the biogeography of fungi remains poorly explored (Lumbsch, Buchanan, May, \& Mueller, 2008; Mueller et al., 2007). The simplest reason is that global fungal diversity is largely unknown. While c. 100,000 species of fungi are described to date, the estimates of global species richness vary between 0.5 and 10 million (Hawksworth \& Lücking, 2017). Most fungi disperse by microscopic windborne spores that can travel across continents. Consequently, scientist in the past suggested that fungal species have cosmopolitan distributions and not be limited by biogeographical contingencies (e.g. Moncalvo \& Buchanan, 2008; Sato, Tsujino, Kurita, Yokoyama, \& Agata, 2012). It is now widely accepted that this is not the case (Hattori, 2017; Peay, Bidartondo, \& Elizabeth Arnold, 2010; Tedersoo et al., 2014), and it has been shown that fungi can be dispersal limited even at small scales (Galante, Horton, \& Swaney, 2011; Norros et al., 2014). Recent studies based on environmental DNA samples have provided the first insights into global soil fungal biogeography and identified climate, edaphic conditions and distance from the Equator to be important predictors for explaining soil fungal richness and community composition (Tedersoo et al., 2014; Treseder et al., 2014).

Europe is the continent with the most advanced knowledge of fungal biodiversity, due to a long tradition of research in fungal taxonomy and biodiversity (Dahlberg, Genney, \& Heilmann-Clausen, 2010). In the last decades, numerous national projects documenting fungal diversity have been initiated, often involving interactive web platforms, which has further contributed to the knowledge of European macrofungi (Andrew et al., 2017; Halme, Heilmann-Clausen, Rämä, Kosonen, \& Kunttu, 2012). Thus far, recording fungal species from reproductive structures (i.e. fruitbodies) has remained the most popular method to inventory macrofungi, although it is also possible to record fungi from vegetative structures (i.e. mycelia) and dormant propagules (i.e. spores).

Aphyllophoroid fungi (non-gilled macrofungi of the Basidiomycota phylum) are the most important agents of wood decay (Stokland, Siitonen, \& Jonsson, 2012), but also include mycorrhizal species, plant pathogens and litter saprotrophs (Tedersoo \& Smith, 2013). Aphyllophoroid fungi are among the best-known groups of macrofungi both globally and in Europe (Bernicchia \& Gorjón, 2010; Ryvarden \& Melo, 2014). From the currently described c. 120,000 species of fungi worldwide (Hawksworth \& Lücking, 2017), aphyllophoroid fungi comprise at least 3,000 species, out of which 1,500 have been considered to occur in Europe (Mueller et al., 2007).

Despite some regional efforts, mainly in boreal Fennoscandia (Kotiranta, Saarenoksa, \& Kytövuori, 2009; Nordén, Penttilä, Siitonen, Tomppo, \& Ovaskainen, 2013), Caucasus (Ghobad-Nejhad, Hallenberg, Hyvönen, \& Yurchenko, 2012) and in the beech distribution area of temperate Europe (Abrego, Bässler, Christensen, \& Heilmann-Clausen, 2015; Abrego, Christensen, Bässler, Ainsworth, \& Heilmann-Clausen, 2017; Heilmann-Clausen et al., 2014), knowledge of aphyllophoroid fungal distribution patterns in Europe is limited. The close associations to live or dead plants in many species suggest 
that vegetation types greatly influence community composition, but it still remains unknown to which degree vegetation zones structure aphyllophoroid fungal communities. A better understanding of how fungal communities depend on their host communities provides the possibility to gain insights into co-evolutionary relationships between fungi and plants (Heilmann-Clausen et al., 2016) and how biogeographical legacies affect current distribution and host-specificity patterns (Auger-Rozenberg, Torres-Leguizamon, Courtin, Rossi, \& Kerdelhué, 2015; Triponez, Arrigo, Espíndola, \& Alvarez, 2015).

In Europe, there is no general congruency among taxonomic groups regarding spatial diversity gradients (Keil et al., 2012). In spermatophyte plants, liverworts and several animal groups, nestedness increases towards the north as a result of the delay in post-glacial recolonization, whereas species turnover increases towards the south, as a response to the lower impact of the Last Glacial Maximum and higher environmental heterogeneity (Hortal et al., 2011; Svenning, Fløjgaard, \& Baselga, 2011). Among bryophytes, liverworts follow the same patterns as spermatophyte plants, whereas mosses follow an inverse pattern, with higher nestedness in the south due to exclusion of drought-intolerant species (Mateo et al., 2016). Yet, regarding spatial community similarity patterns, European mammal and plant communities show congruent cluster configurations (Heikinheimo et al., 2012).

In this study, we analysed the biogeographical structure of aphyllophoroid fungi in Europe, including selected adjacent areas. We compiled a dataset which covered nearly all European aphyllophoroid fungi (Mueller et al., 2007). Our extensive dataset consisted of 14,030 occurrences of 1,491 aphyllophoroid species recorded from fruitbody surveys across 39 European areas in 17 countries. We first analysed patterns of fungal alpha and beta diversity in relation to the plant-based biogeographical regions developed by the European Environmental Agency (EEA, 2015) and in relation to the areas' location in southern versus northern Europe. Second, we classified the areas in relation to their fungal community composition (in terms of overall beta diversity and its turnover and nestedness components). Finally, we modelled the fungal community composition and species richness of the studied areas in relation to biogeographical region, climate, host-tree distributions, topography and land-use intensity across Europe. Given previous knowledge about host-tree specificity of many aphyllophoroid fungi, our working hypothesis was that plant-based biogeographical regions largely determine the distributions and diversity of European aphyllophoroid fungi. Further, we expected species richness to decrease and nestedness to increase towards the north, reflecting decreasing diversity in host-plant species.

\section{2 | MATERIALS AND METHODS}

\section{1 | Fungal dataset}

Fungal datasets were assembled by the approach described by Hortal (2008) as "aggregating survey records," which assumes assembling local checklists from sites of known limits and areas of varying size.
Species lists from 39 European areas including adjacent southern geographical areas (Palestine and the south-east coast of the Caspian Sea) and Subarctic to Arctic islands (Greenland, Faroe Islands, Iceland, Svalbard) were compiled into a presence-absence data matrix (Appendix S1.1). In most cases, the areas were defined by administrative boundaries and correspond to governmental districts, regions, federal states, or in the case of small countries, to the whole countries. The size of the areas ranged from 48 to $102,000 \mathrm{~km}^{2}$. Areas were selected to represent the biogeographical regions of the European Environment Agency system (EEA, 2015) as equally as possible. To ensure comparability, only areas and data generated from 1994 onwards were considered. By this time, most of the still current important continental-scale identification key books had been published (Hjortstam, Larsson, Ryvarden, \& Eriksson, 1988; Ryvarden \& Gilbertson, 1994). Authors of this study provided species lists for 16 areas, and the rest were obtained from literature or web sources (Appendix S1.2). Detailed information on the selected areas is provided in Appendix S2, and their locations are shown in Figure 1. All species names were updated according to the database Index Fungorum (2015).

We pooled all environmental data for administrative units, by assuming homogeneity on the environmental conditions within these, and thus comparable size and effort in fungal diversity exploration. In the statistical analyses, this was further handled by resampling techniques (permutations, bootstraps) and cross-examining the robustness of the results by applying various methods (see Section 2.3).

To study the variation of diversity in latitudinal gradient, we split our dataset into areas representing northern and southern Europe, using the geographical latitude of $50^{\circ}$ as threshold, in line with the studies of Baselga (2010), Freijeiro and Baselga (2016) and Mateo et al. (2016). This resulted in 15 and 24 areas representing northern and southern European bands, respectively. The two datasets were thoroughly compared in terms of diversity, using resampling methods described in Section 2.3.2.

\subsection{Selected environmental variables}

Apart from the classification of each of the areas into biogeographical regions following EAA (2015), we obtained data on several variables potentially driving species composition using QGis 2.10 software (http://www.qgis.org/). Climatic data were extracted from the WorldClim 1.4 database (Hijmans, Cameron, Parra, Jones, \& Jarvis, 2005). We selected climatic variables which were not strongly correlated (Pearson's $r<.7$ ), and so we retained annual mean temperature (BIO1), total precipitation (BIO12), seasonal variation of these two parameters ( $\mathrm{BIO} 4$ and $\mathrm{BIO} 15$, respectively) and mean temperature of the wettest quarter (BIO8).

The distribution data of the 15 most common European tree genera/species (taxonomic resolution varied in the original dataset) were obtained from Brus et al. (2012). We calculated the relative occupancy of each tree taxon (further referred to as tree species) in each area in two steps: first, we summed the proportions of the land 


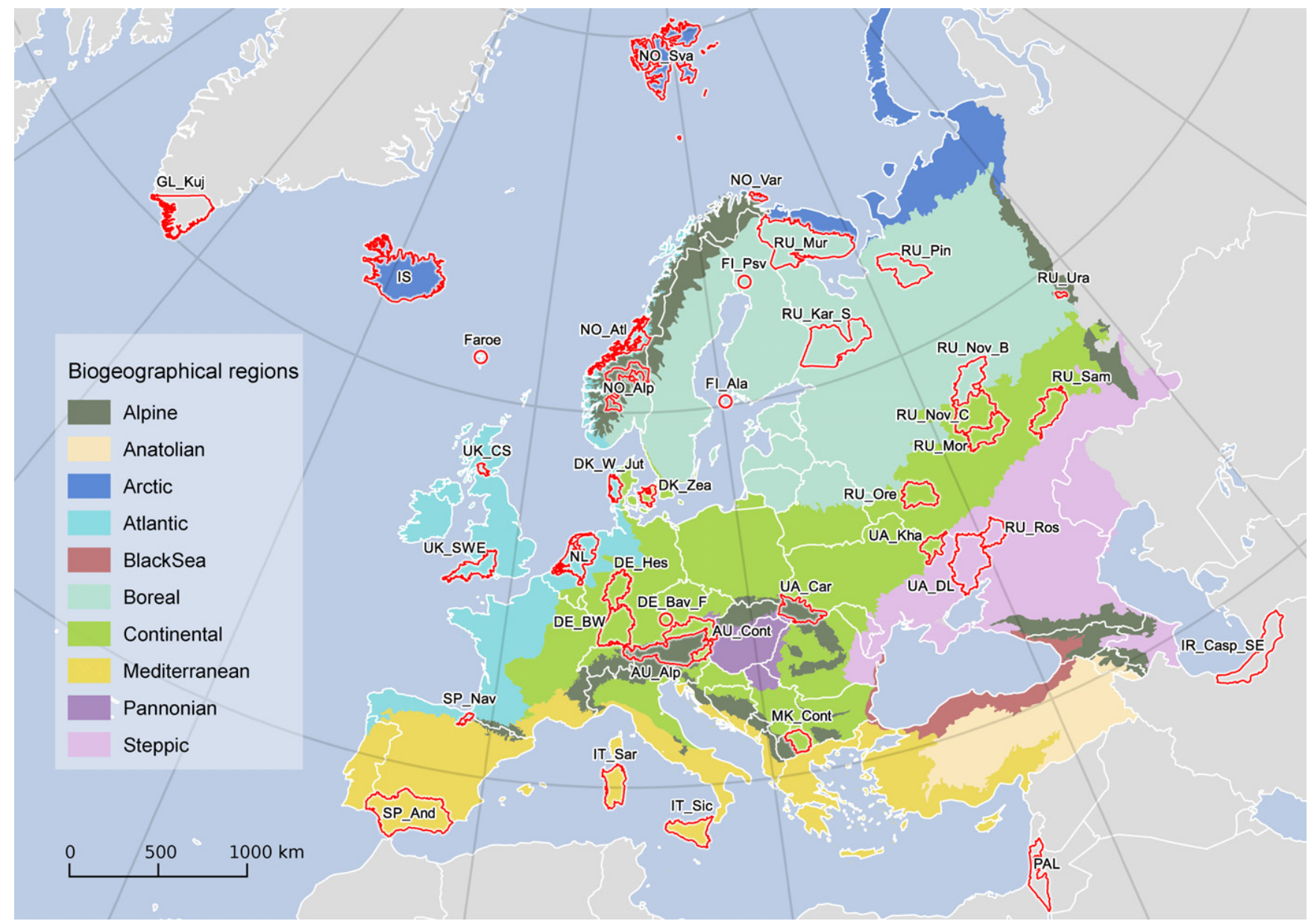

FIGURE 1 Map of Europe showing the locations of the areas included in the study, and their assignment to the biogeographical regions. The full names of the areas are provided in Appendix S1

area covered by each tree species in all $1 \times 1 \mathrm{~km}$ quadrats within the areas. Second, the obtained values were divided by the total number of the quadrats in the area to account for the non-forested areas. For the 16 areas that were not covered either by Brus et al. (2012), we generated relative occupancies as the average values per biogeographical region to which the given area belongs (mean substitution in terminology of Hill \& Lewicki, 2006). For the south-east coast of the Caspian Sea in Iran, the mean values for the whole dataset were applied. We used the Human Footprint score (mean value for area) as an integrated measure of land-use intensity (Sanderson et al., 2002; WCS \& CIESIN, 2005).

Finally, we calculated topographical variables of area size, perimeter, mean altitude, and geographical coordinates of the areas' centroids.

\section{3 | Statistical analyses}

\subsubsection{Gamma diversity and local species richness}

All statistical analyses were carried out using R 3.3.2 (R Core Team, 2016). Gamma diversity (i.e. the total species richness of aphyllophoroid fungi in Europe) was assessed in two ways: by constructing a sample-based accumulation curve (each area was considered a sample unit) and by applying several species richness estimators (Chao 2, Jacknife 1, Jacknife 2 and Bootstrap). All calculations were performed by applying 100 permutations at each step and ordering the areas randomly without replacement with the "speccacum" function of the "vegan" package (Oksanen, Blanchet, Kindt, Legendre, \& O'Hara, 2016).

We calculated the local species richness of aphyllophoroid fungi in the European areas by summing their presences in each area. To study the relationship between species richness and environmental variables, we fitted generalized linear models (GLM) of the negative binomial family with log link function, using the "glm.nb" function from the "MASS" package (Venables \& Ripley, 2002). We identified the best predictor variables by a forward selection procedure based on Akaike information criterion (AIC), using the function "stepAIC" of the basic "stats" package. Variable selection was carried out separately for each group of predictors (climatic variables, tree species, topography and land-use intensity). In each case, variables were introduced into the model in descending order reflecting their independent contribution (from greatest to least) for explaining unadjusted deviance in the response variable (Appendix S3.1). Unadjusted deviance $\left(D^{2}\right)$ was retrieved from the fitted models with the 
"Dsquared" function of the "modEvA" package (Barbosa, Brown, Jimenez-Valverde, \& Real, 2016), and is a direct analogue of the $R^{2}$ in the least squares linear regression. We included only significant variables from each group (climatic, tree occupancies and land-use intensity) to select the most parsimonious models, and topographical variables (area size, longitude and latitude) were always added, regardless of significance, to account for the differences in areas' size and location. To study directly the effect of the areas' biogeographical classification on the species richness, we built models including plant-based biogeographical classification of the areas (EAA, 2015), topography and land-use intensity (hereinafter called main models). We also built alternative models where areas assignment to biogeographical regions was replaced by the climatic variables and tree species occupancies.

The significance of the most parsimonious models was tested with the sequential likelihood ratio tests provided by "anova.negbin" function from the "MASS" package. The overall goodness-of-fit of the final models was assessed with a chi-squared test based on the residual deviance and degrees of freedom, models' AIC values, and $D^{2}$ (Appendix S3.2).

\subsection{2 | Beta diversity}

To evaluate differences in species composition across Europe, we applied the analytical framework of Baselga (2010), which decomposes beta diversity into the species turnover and nestedness components. For measuring beta diversity overall, we calculated multiplesite generalization of the Sørensen dissimilarity and derived from it multiple-site dissimilarity measures of turnover and nestedness (BaseIga, 2010), using "beta.multi" and "beta.sample" functions of the "betapart" package (Baselga \& Orme, 2012). In this context, turnover is defined as the dissimilarity caused by substitution, of some species by others from one sampling unit to another, controlling for species richness differences. Nestedness is defined as a structured case of species richness difference, reaching the highest values when species in given species poor area are a perfect subset of species occurring in more species-rich areas (Baselga \& Leprieur, 2015).

To assess the variation of beta diversity across Europe, we compared multiple-site dissimilarity measures of Sørensen, turnover and nestedness between northern and southern Europe, with the permutation test, using "sample" function of the basic "base" package (Appendices S3.3 and S3.4). To obtain an equal sampling effort in the two sectors, we resampled randomly and with replacement 10 areas within each of the datasets 1,000 times. For each iteration, we pooled the community data from the two European sectors together $(10+10=20$ areas). We then calculated multiple-site beta diversity for northern and southern European areas. We subtracted the lower multiple-site dissimilarity value from the higher value and generated the distribution of the dissimilarity differences under null hypothesis. We estimated the significance in the differences using a permutation tests (Collingridge, 2013).

To assess pairwise differences in the species compositions between areas, we calculated Sørensen (1948) pairwise dissimilarity index, as well as its two components: pairwise dissimilarity index of Simpson (1943) which evaluates turnover, and the nestedness index developed by Baselga (2010). All three pairwise indices were calculated and automatically arranged into three symmetric matrices (hereinafter called Sørensen, turnover and nestedness matrices) with the "beta.pair" function of the "betapart" package (Baselga \& Orme, 2012).

We further assessed whether the pairwise Sørensen, turnover and nestedness-resultant dissimilarities increase with a different rate along the spatial distance between northern and southern Europe (Appendices S3.5 and S3.6). We first correlated (Pearson r) community dissimilarities to the spatial distances between areas and verified the significance of correlations with the Mantel test using "vegan" package. For each beta-diversity component, we compared correlations with the distance by means of permutation test using "sample" function of the basic "base" package. To generate parameter distribution under null hypothesis, we first pooled equal number of data from southern and northern Europe (100 bound beta dissimilarity/ spatial distance values in each case, selected with replacement), repeating this procedure 1,000 times. For each iteration, we pooled the data from the two European sectors together $(100+100=200$ rows). We then classified the areas as northern or southern areas, and we calculated Pearson $r$ for each of the groups. We estimated the significance of differences in the $r$ value using a permutation test (Collingridge, 2013).

\subsection{3 | Clustering based on beta diversity}

To reduce the dimensionality of each of the three dissimilarity matrices and identify groups of areas with similar fungal assemblages, we applied a clustering procedure. We tested the performance of four clustering methods (unweighted pair-group method based on arithmetic averages [UPGMA], Ward's, Neighbour Joining and DIANA), of which UPGMA performed the best (see details in Appendices S3.7 and S3.8). We evaluated uncertainties in the resulting UPGMA dendrograms using the multiscale bootstrap procedure (see details of calculations in Appendix S3.9) with the "recluster" package (Dapporto et al., 2013).

\subsection{4 | Factors influencing beta diversity}

We evaluated the effects of the environmental variables separately for the Sørensen, turnover and nestedness matrices. For this, we performed constrained analysis of principal coordinates (CAP) on original dissimilarity matrices (without any transformations) using the "capscale" function of "vegan" package. The environmental variables were scaled to zero mean and unit variance prior to analyses (option "standardize" in the "decostand" function of "vegan") (Borcard, Gillet, \& Legendre, 2011; Legendre, 2014). We identified the best predictor variables by forward selection procedure based on AIC followed by the permutation test (100 iteration steps of dropping and adding terms and performing 1,000 permutations), using the function "ordistep" of the "vegan" package. We carried out the variables selection 
separately for each group of predictors (climatic variables, tree species relative occupancies, topography and land-use intensity). We included only significant variables to produce the most parsimonious models, but added the topographical variables (area, longitude and latitude) in all final models, to account for the differences in areas size and location (Appendix S3.2). We tested the significance of the most parsimonious models using a permutation test (1,000 replications) with the "anova.cca" function of "vegan" package. For the most parsimonious models, we calculated the proportion of variation explained uniquely by each of the predictor's group via variation partitioning ("varpart" function of "vegan" package), supported by permutation tests (1,000 replications; Oksanen et al., 2016).

To study directly the effect of the areas' biogeographical classification on the community composition, we built CAP models with single categorical variable specifying the assignment of each area to the European biogeographical regions (EAA, 2015) as well as topography and land-use intensity. To disentangle the effect of biogeography on community composition, we built also alternative CAP models where the assignment to the biogeographical regions was replaced by the variables characterizing climate and tree occupancies.

\section{3 | RESULTS}

\subsection{Gamma diversity and local species richness}

From the 39 European areas, we assembled 14,030 records of 1,491 fungal species (Figure 2). The species accumulation curve indicated a very thorough sampling of European aphyllophoroid species in our data, but richness estimators indicated the total species richness to be $142-461$ species larger than observed (Figure $2 b$ ).

Among the plant-based biogeographical regions, the Arctic region held the fewest species (52.6 on average), while the Alpine, Atlantic, Boreal and Continental biogeographical regions all harboured at least 200 species (404.9 on average) with no significant differences (a)

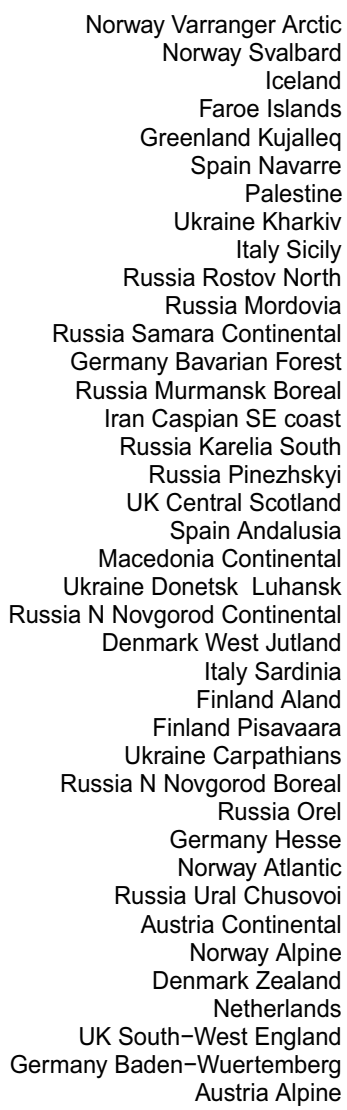

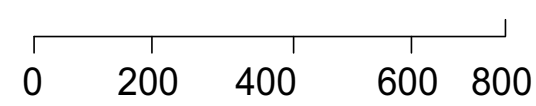

(b)

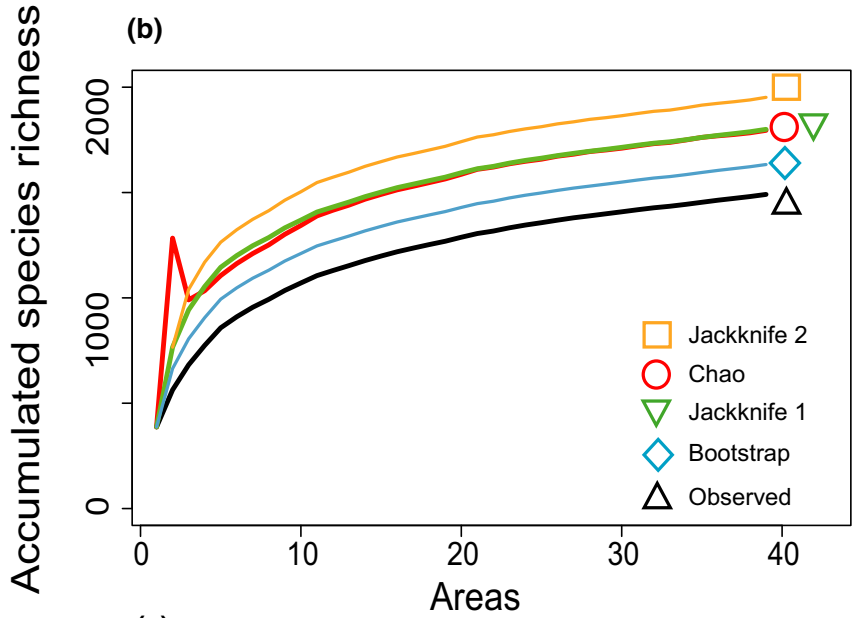

(c)

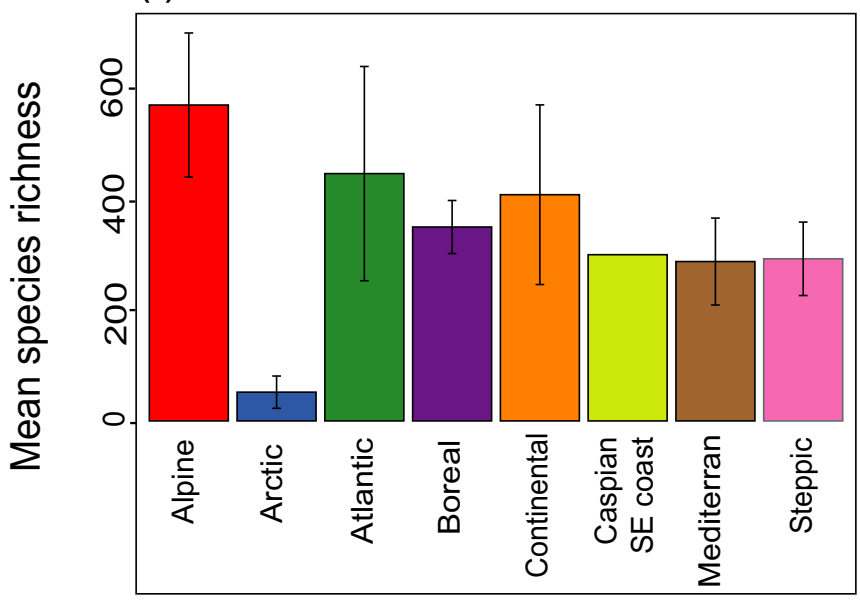

Biogeographical regions

FIGURE 2 Gamma diversity and local species richness of aphyllophoroid fungi in Europe: (a) bar chart showing the species richness in the 39 areas included in the study, (b) species accumulation curves for the pooled observed species in the studied areas, and corresponding species accumulation curves for the estimated (Chao 2, Jacknife 1, Jacknife 2 and Bootstrap) species richness, (c) mean species richness with standard deviations for the areas located within the European biogeographical regions. Colours in (a) and (c) are identical in terms of displaying European biogeographical regions 
among regions. However, there was a clear trend of decreasing species richness towards the southern biogeographical regions (Mediterranean-291.5 species, Steppic - 296.5 species, and south-east coast of the Caspian Sea-304.0 species) (Figure 2a,c).

The main model explained $84.7 \%$ of the variation in the species richness. This result is largely due to the plant-based biogeographical classification which solely explained $74 \%$ of the variation, while topography and human land-use individually explained only $6.5 \%$ and $8.6 \%$ of the variation in the species richness (Table 1 , Appendix S3.10). The alternative model explained $57 \%$ of the variation in species richness and was equally explained by climate (significant variables of mean temperature of the wettest quarter and annual precipitation) and tree species (significant variables Betula, Fraxinus and Larix), which explained $20.3 \%$ and $20.5 \%$ of the variation in species richness, respectively.

\section{2 | Beta diversity}

The Sørensen beta-diversity value for the fungal dataset was 0.92 . The turnover component of beta diversity dominated over the nestedness component ( $\beta_{\mathrm{SIM}}=0.84$ vs. $\beta_{\mathrm{SNE}}=0.08$ ), resulting in the proportional contributions to the total beta diversity of $91 \%$ and $9 \%$, respectively.

Overall, Sørensen beta diversity, as well as turnover and nestedness, was higher in northern compared with southern Europe based on the original datasets (Appendices S3.3 and S3.4). However, the multiple-site dissimilarity analysis (i.e. equal-size resampled data) revealed that the Sørensen and nestedness dissimilarities were higher in southern Europe. Nevertheless, these differences were all insignificant based on permutation tests.

Pairwise dissimilarities between 39 areas calculated with the Sørensen, turnover and nestedness indices and imposed on the map of Europe are available in Appendix S3.5. Assemblage dissimilarities were mostly positively related to spatial distances (Pearson $r$ between .254 and .442, $p<.01$; Figure 3 ). The strength of relationship was not different between southern and northern Europe (Appendix S3.6).

\section{3 | Clustering based on beta diversity}

Three UPGMA trees were produced based on the selected distance matrices. The clustering based on Sørensen matrix showed generally short distances among the dendrogram fusion levels (Figure 4a). All Arctic areas took basal positions and aggregated into two groups (two Norwegian Arctic areas branched out first, then three other Arctic areas). Non-Arctic areas formed a well-supported cluster but with biogeographical regions somewhat intermixing. The cluster with Mediterranean areas additionally included Macedonia (continental) and south-east coast of the Caspian Sea, and Atlantic areas were mainly clustered with Continental areas. A pure Boreal cluster was limited to three areas of Boreal Russia. The clustering based on the turnover matrix resulted in the least defined hierarchical structure with large intermixing of areas from different biogeographical regions
(Figure 4b). Finally, the clustering of the nestedness matrix revealed three principal clusters. The cluster of five Arctic areas gained the highest bootstrap support. The second large cluster included Alpine, Atlantic and two species-rich Continental areas (Zealand of Denmark and Baden-Württemberg of Germany). The third large cluster included majority of Continental areas together with all Boreal, Mediterranean, Steppic areas and south-east coast of the Caspian Sea (Figure 4c).

\subsection{Factors influencing beta diversity}

The main model explained $59.1 \%$ of variation in Sørensen distances (Table 1, Appendix S3.10). Plant-based biogeographical classification contributed $30.6 \%$ to the total variation, while topography contributed $10.9 \%$ and land-use intensity $3.8 \%$. The alternative model explained $56.6 \%$ of variation in Sørensen distances. In the alternative model, variation in Sørensen distances was significantly related to climate, topography and land-use intensity but not to tree occupancies (Figure 5a). Climatic variables contributed $14.8 \%$ to the total variation, topographical variables $7.9 \%$ and land-use intensity $4.6 \%$.

The main model for species turnover explained $39.2 \%$ of variation (Table 1, Appendix S3.10). Variation in species turnover was significantly related to topography and land-use intensity but not to plant-based biogeographical classification. Topography contributed $11.2 \%$ to the total variation, while land-use intensity $3.5 \%$. The alternative model for species turnover explained $49 \%$ of variation and showed that species turnover was significantly related to climate and tree occupancies which explained $12.9 \%$ and $10.5 \%$ of the variation (Figure $5 b)$. Topography was nearly significant $(p=.053)$ and explained $8.2 \%$ of the variation in species turnover.

Finally, the main model for nestedness explained $76.2 \%$ of the variation (Table 1, Appendix S3.10). The very strong and the only significant contributor to it was plant-based biogeographical classification which explained $63.6 \%$ of variation in nestedness. The alternative model accounted for $50.2 \%$ of the total variation in nestedness. Most of this variation was due to the tree occupancies, principally due to Betula and Larix (31.1\%; Figure 5c). Climate (variable mean temperature of the wettest quarter) explained $6.1 \%$ of the variation in the alternative model for nestedness.

\section{4 | DISCUSSION}

Our results show that the importance of biogeographical regions in determining European aphyllophoroid fungal communities varies for different diversity components. The species richness of aphyllophoroid fungi is mostly explained by plant-based biogeographical regions, with Arctic and Mediterranean regions holding fewer species than the other regions. Biogeographical regions defined for plant communities are equally important as variation in climate and tree species composition for explaining overall beta diversity. Yet, biogeographical regions are most important for explaining species nestedness, while for species turnover, which is the main driver behind 
TABLE 1 Outputs of the most parsimonious models for aphyllophoroid fungal species richness, Sørensen dissimilarity, species turnover and nestedness in Europe. For each of the response variables, a main model (including biogeographical regions, topography and land-use intensity) and an alternative model (where biogeographical regions were replaced by climatic variables and tree species occupancies; topography and land-use intensity were kept) were fitted. The outputs for species richness correspond to negative binomial generalized linear models (GLM) run independently for each variable group. The outputs for Sørensen dissimilarity, species turnover and nestedness correspond to results of the constrained analysis of principal coordinates (CAP) after variation partitioning, that is, unique effects of each variable groups are provided

\begin{tabular}{|c|c|c|c|c|c|c|c|c|c|}
\hline $\begin{array}{l}\text { Explanatory variables for } \\
\text { species richness }\end{array}$ & $\begin{array}{l}\text { Dispersion } \\
\text { parameter } \\
\text { theta }\end{array}$ & $D^{2}$ & $D_{\text {adj }}^{2}$ & AIC & $\begin{array}{l}\text { Null } \\
d f\end{array}$ & $\begin{array}{l}\text { Null } \\
\text { deviance }\end{array}$ & $\begin{array}{l}\text { Residual } \\
d f\end{array}$ & $\begin{array}{l}\text { Residual } \\
\text { deviance }\end{array}$ & $p$ \\
\hline Main model & 16.491 & 0.847 & 0.776 & 473.15 & 38 & 256.021 & 27 & 39.195 & .061 \\
\hline Biogeographical region & 9.58 & 0.74 & 0.67 & 486.34 & 38 & 154.248 & 31 & 40.154 & .126 \\
\hline Topography & 2.649 & 0.065 & -0.045 & 530.25 & 38 & 44.414 & 35 & 41.543 & .207 \\
\hline Land-use intensity & 2.857 & 0.134 & 0.086 & 523.04 & 38 & 47.84 & 37 & 41.419 & .284 \\
\hline Climate & 3.095 & 0.203 & 0.134 & 521.64 & 38 & 51.749 & 36 & 41.262 & .251 \\
\hline Tree species & 3.107 & 0.205 & 0.111 & 523.52 & 38 & 51.942 & 35 & 41.297 & .215 \\
\hline Topography & 2.649 & 0.065 & -0.045 & 530.25 & 38 & 44.414 & 35 & 41.543 & .207 \\
\hline Land-use intensity & 2.857 & 0.134 & 0.086 & 523.04 & 38 & 47.84 & 37 & 41.419 & .284 \\
\hline Topography & & .109 & 0.081 & 73.581 & 3 & \multicolumn{2}{|l|}{0.786} & 2.407 & .001 \\
\hline Land-use intensity & & .038 & 0.031 & 75.329 & 1 & \multicolumn{2}{|l|}{0.274} & 2.519 & .001 \\
\hline Alternative model & & .566 & 0.366 & 69.356 & 12 & \multicolumn{2}{|l|}{4.072} & 2.828 & .001 \\
\hline Climate & & .148 & 0.079 & 70.455 & 5 & \multicolumn{2}{|l|}{1.064} & 1.774 & .002 \\
\hline Tree species & & .092 & 0.055 & 75.722 & 3 & \multicolumn{2}{|l|}{0.664} & 1.845 & .07 \\
\hline Topography & & .079 & 0.039 & 73.581 & 3 & \multicolumn{2}{|l|}{0.572} & 1.588 & .025 \\
\hline Land-use intensity & & .046 & 0.041 & 75.329 & 1 & \multicolumn{2}{|l|}{0.328} & 2.732 & .005 \\
\hline Explanatory variables for $t$ & over & $R^{2}$ & $R_{\text {adj }}^{2}$ & AIC & $d f$ & \multicolumn{2}{|c|}{ Sum of squares } & Pseudo- $F$ & $p$ \\
\hline Main model & & .392 & 0.144 & 74.178 & 11 & \multicolumn{2}{|l|}{2.764} & 1.583 & .001 \\
\hline Topography & & .082 & 0.030 & 74.178 & 3 & \multicolumn{2}{|l|}{0.578} & 1.392 & .053 \\
\hline Land-use intensity & & -.0002 & -0.028 & 76.717 & 1 & \multicolumn{2}{|c|}{-0.002} & -0.013 & .959 \\
\hline Explanatory variables for & edness & $R^{2}$ & $R_{\mathrm{adj}}^{2}$ & AIC & $d f$ & \multicolumn{2}{|c|}{ Sum of squares } & Pseudo-F & $p$ \\
\hline Main model & & .762 & .665 & -14.272 & 11 & \multicolumn{2}{|l|}{1.217} & 7.858 & .001 \\
\hline Biogeographical region & & .636 & .642 & -14.272 & 7 & \multicolumn{2}{|l|}{1.016} & 10.303 & .001 \\
\hline Topography & & .075 & .061 & - & 3 & 0.119 & & 2.824 & .08 \\
\hline Land-use intensity & & .012 & .005 & 13.335 & 1 & 0.02 & & 1.414 & .284 \\
\hline Alternative model & & .502 & .39 & -2.991 & 7 & 0.803 & & 4.471 & .004 \\
\hline Climate & & .061 & .054 & 11.443 & 1 & 0.098 & & 3.807 & .046 \\
\hline Tree species & & .311 & .322 & 11.481 & 2 & 0.497 & & 9.698 & .001 \\
\hline Topography & & -.037 & -.095 & - & 3 & -0.059 & & -0.772 & .996 \\
\hline Land-use intensity & & .001 & -.018 & 13.335 & 1 & 0.001 & & 0.039 & .762 \\
\hline
\end{tabular}

Italics indicates the complete statistical models (main and alternative models) 
Southern Europe
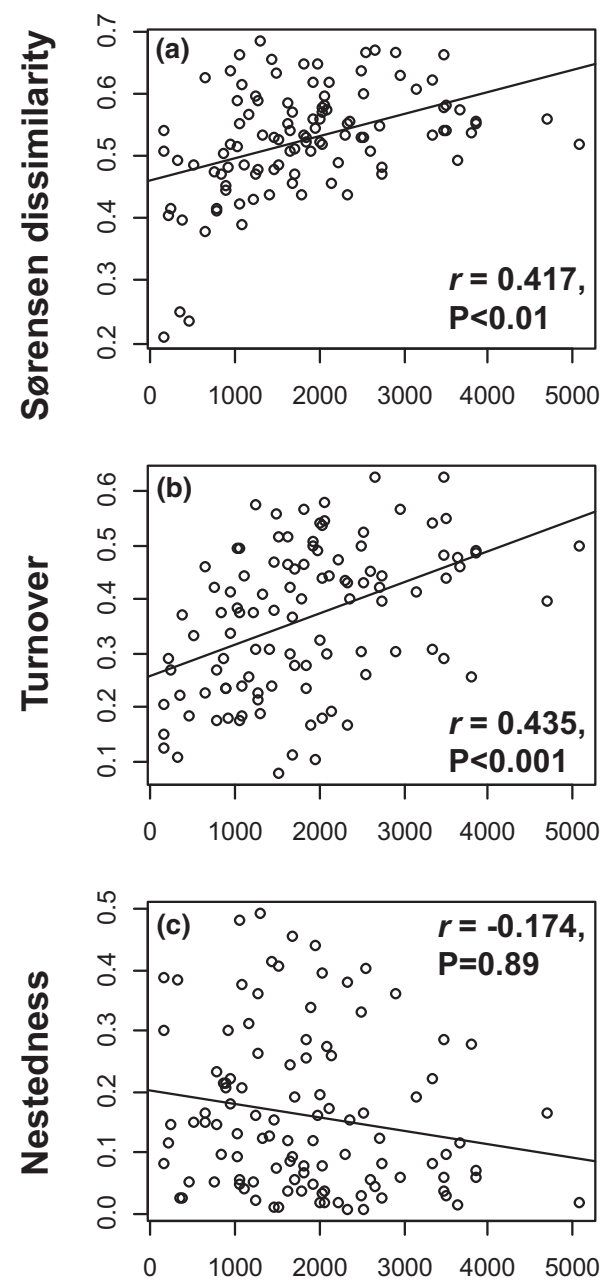

Northern Europe
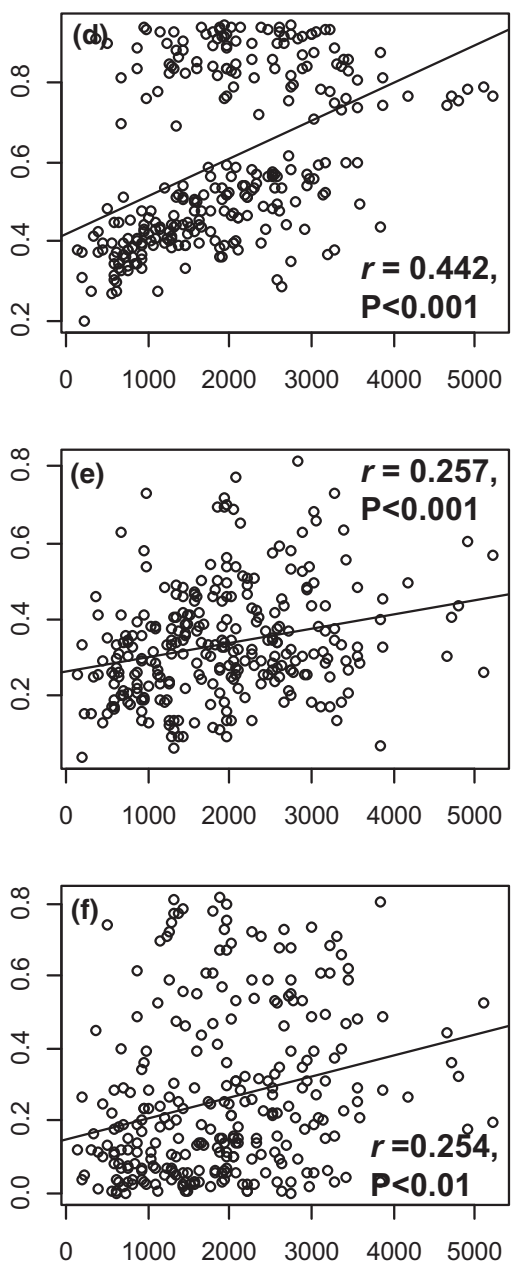

\section{Geographic distance $(\mathrm{km})$}

FIGURE 3 Relationship between pairwise areas dissimilarities of aphyllophoroid fungi (Sørensen, turnover and nestedness) and geographical distances in southern $(\mathrm{a}-\mathrm{c})$ and northern Europe $(\mathrm{d}-$ f): Pearson correlations ( $r$ ) with significance values $(P)$ from Mantel tests overall beta-diversity patterns, variation in climate and tree species composition are the most influential factors.

The lowest aphyllophoroid species richness and highest nestedness was found in Arctic areas. Since many aphyllophoroid fungi are associated with dead wood, this is not surprising as the diversity of woody hosts and amounts of dead wood are very limited in Arctic areas. Results from recent studies suggest that aphyllophoroid fungal communities in Arctic areas are to a large extent explained by arrival of pre-colonized driftwood which originates from non-Arctic parts of Europe, Asia and North America (Rämä et al., 2014; Ryvarden, 2015). Hence, the low diversity of aphyllophroid fungi in Artic regions may also reflect dispersal limitation. Further, our analysis of the nestedness showed that Arctic communities were strongly influenced by the mean temperature of the wettest quarter. This points to a direct climatic limitation which could reflect that fruiting of fungi is inhibited at low temperatures (Sato et al., 2012). Interestingly, we also found a trend of decreasing species richness and increasing turnover towards southern areas (Mediterranean, Steppic biogeoregions and south-east coast of the Caspian Sea). These regions are the richest in plant species and also support the highest diversity of woody hosts. Studies from other continents support the finding that the highest aphyllophoroid fungal species richness is

FIGURE 4 UPGMA dendrograms based on the Sørensen dissimilarity (a), and its turnover (b) and nestedness (c) components for the aphyllophoroid fungi in the 39 European areas included in this study. Area labels were coloured according to their assignment to the European biogeographical regions. Each dendrogram is a 50\% consensus tree obtained after 100 random re-arrangements of the matrix. The values at the nodes indicate the branch support from ordinary bootstrapping (left) and multiscale bootstrapping from $5 \times$ increased species pool (right). The nodes which have been identified to have consistent increase in support or no consistent increase in support during the steps of multiscale bootstrapping are shown in black and red, respectively (see Section 2 and Appendix S3.9 for a statistical explanation). The line charts accompanying each dendrogram show the magnitude of the node height changes during the procedure of hierarchical clustering 
(a)

Sørensen dissimilarity
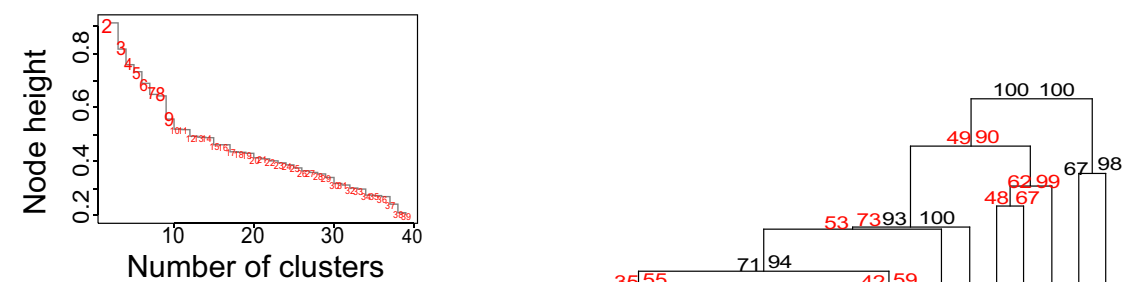

Biogeographical regions:

Alpine

Arctic

Atlantic

Boreal

Continental

Caspian SE coast

Mediterranean

Steppic

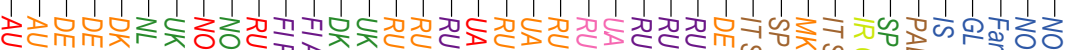

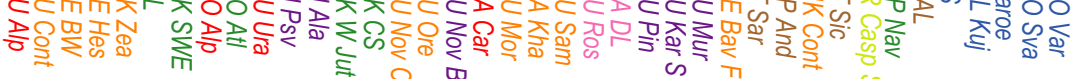

(b)

\section{Turnover}
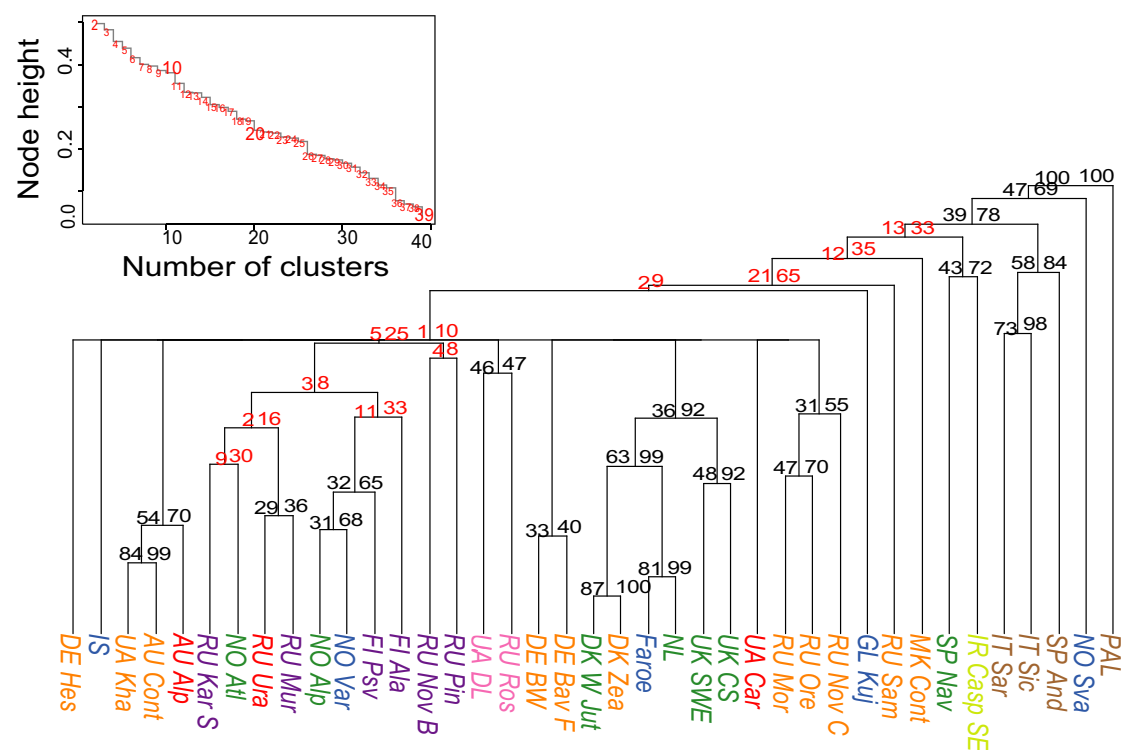

(c)

Nestedness

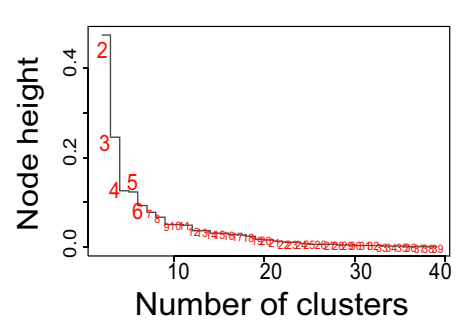

100100

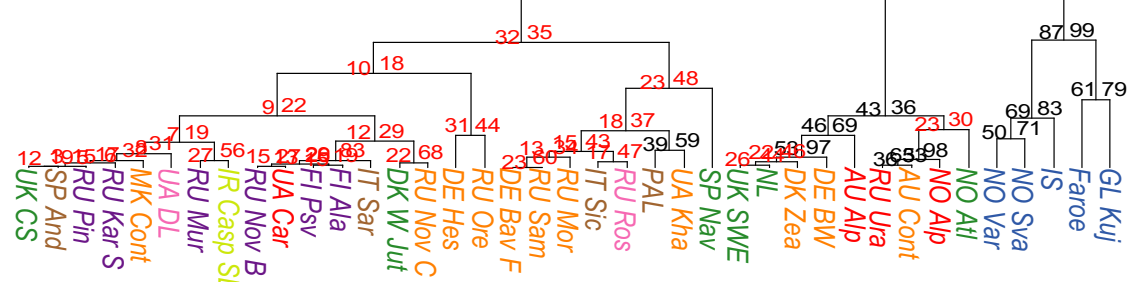


(a)

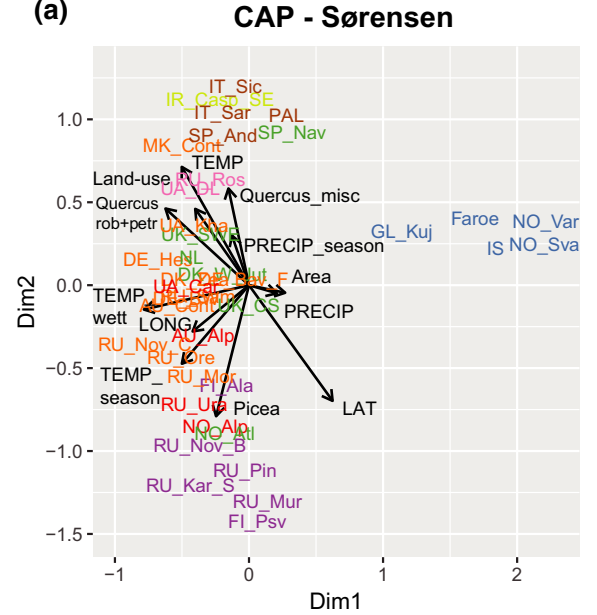

(b)

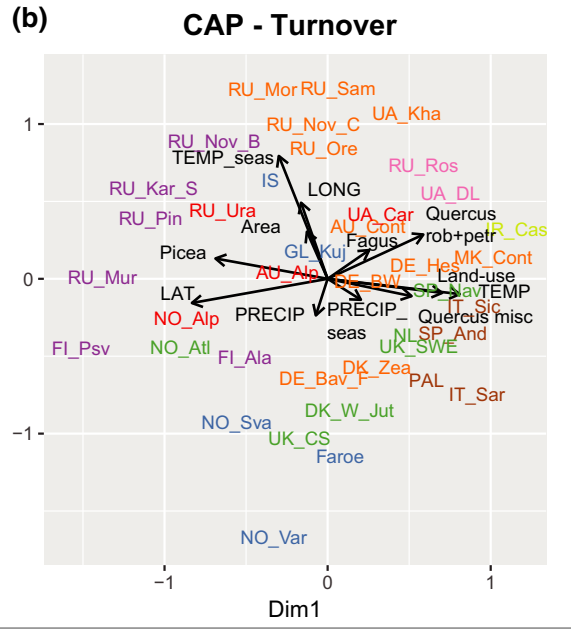

(c)

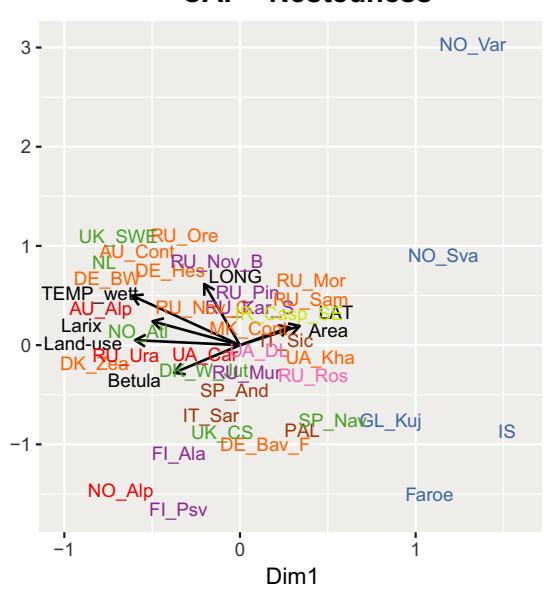

Biogeographical regions: Alpine Arctic

Atlantic Boreal Continental

Mediterranean

Steppic

FIGURE 5 Constrained analyses of principal coordinates (CAPs) showing relationship between four groups of environmental variables: climate, tree occupancies, topography and land-use intensity, and beta diversity of aphyllophoroid fungi in Europe expressed as Sørensen dissimilarity (a), turnover (b) and nestedness-resultant dissimilarity (c). Only those environmental variables which were selected to the respective most parsimonial alternative CAP models were displayed. Abbreviations: TEMP $=$ mean annual temperature, TEMP_seas $=$ temperature seasonality, TEMP_wett $=$ temperature of the wettest quarter, PRECIP $=$ annual precipitation, PRECIP_seas $=$ precipitation seasonality, LAT $^{=}$latitude, $L O N G=$ longitude

found at middle latitudes and decreases towards the north and south (Gonzalez-Avila, Luna-Vega, Garcia-Sandoval, \& Contreras-Medina, 2016; Mukhin, 1993; Shiryaev, 2014), indicating that aphylloporoid fungal diversity might generally be lower in warm and/or dry regions. This could reflect that the often long-lasting aphyllophoroid fruitbodies are poorly adapted to stressful climates, which typically involve strong fluctuations in humidity and extreme temperatures. Shift to insect-driven wood decomposition, which is enhanced in warmer climates (e.g. Müller et al., 2015), may be a further explanation to the lower aphyllophoroid diversity in these regions.

A negative effect of land-use intensity was evident for species richness but not for community composition, and geographical variables were rather weak predictors of both species richness and community composition. This contrasts with results from European vascular plants and animals, for which the effect of non-climatic variables such as land-use intensity and geographical distance was found to be strongest (Keil et al., 2012; Svenning, Normand, \& Skov, 2008; Svenning et al., 2011). Therefore, our results suggest that aphyllophoroid fungal communities are less shaped by historical legacies than plant and animal communities, at least at the continental scale. Furthermore, both multiple-site and spatial beta diversity analyses showed that the beta-diversity gradients were similar in southern and northern Europe. Hereby, our results resemble those obtained for bryophytes (in particular mosses), for which no differences in turnover and nestedness between southern and northern Europe have been detected (Mateo et al., 2016), indicating that climate and current habitat availability to be the main drivers of community composition.

Although tree species composition was one of the main factors influencing the turnover in aphyllophoroid communities, we expected this variable to be even more influential. Many of our study species are plant-associated with prominent host-specializations, and communities of aphyllophoroid fungi found in conifer forests differ strongly from those found in deciduous forests (Hattori, 2005; Stokland et al., 2012). However, Heilmann-Clausen et al. (2016) recently found that major clades of aphyllophoroid fungi are less host specialist than several other fungal lineages, especially in the Ascomycota, probably reflecting a much stronger signal of co-evolution with hosts. It is, hence, likely that host distribution patterns may have a stronger impact on the biogeography of fungi in other lineages than aphyllophoroid fungi, as it has been found in Lepidoptera with strong coevolution with their plant hosts (Auger-Rozenberg et al., 2015; Triponez et al., 2015).

We found that aphyllophoroid fungal communities followed plant-based biogeographical regions to a large extent, but not as clearly as animal and plants (Heikinheimo et al., 2012). The clearest cluster in terms of community composition was formed by Arctic areas, most likely reflecting the low aphyllophoroid species richness in these areas. The cluster analyses also revealed that Mediterranean areas, south-east coast of the Caspian Sea and Steppic areas hold similar community composition. Mediterranean areas and south-east coast of the Caspian Sea share a long history of similar climate and vegetation and represent glacial refugia for temperate European forest trees (Ghobad-Nejhad et al., 2012; Magri et al., 2006). A partly similar climate and geographical proximity of Steppic areas to Mediterranean areas and south-east coast of the Caspian Sea may be a reason for their high similarity in fungal community composition. The community composition of Alpine, Atlantic, Boreal and Continental areas formed more complex cluster configurations. One of the reasons for this might be that some of the areas are located close to ecotones between biogeoregions and thus resemble the 
communities from neighbouring biogeoregions. For instance, the fungal composition of the Navarre (northern Spain), dominated by temperate beech forests, was more similar to Mediterranean areas than to other Atlantic areas. Likewise, the Continental area of Macedonia was closer to the Mediterranean biogeoregion than to other Continental areas. Another reason for the intermixing of biogeoregions might fall on the sensitivity of fungi to particular climatic conditions. For example, the Bavarian Forest, situated in area classified as Continental, held fungal community which clustered with Atlantic and Arctic areas, which might be explained by the high precipitation in this area (Bässler, Müller, Dziock, \& Brandl, 2010).

The present study provides an integrated overview of alpha- and beta-diversity patterns for European aphyllophoroid fungi and reveals the drivers of the diversity patterns in this important group of organisms. In spite of the comprehensive dataset we used, we still found ambiguities when trying to biogeographically classify the study areas. To overcome this problem, future studies in this line of research could use data collected by a regular-grid or with a finer spatial resolution than in our study and include some of still largely unexplored European areas (e.g. north-western Europe). Moreover, comparing the spatial patterns of the species with different fruitbody traits, ecological strategies and phylogenetic relationships would help in gaining a more functional perspective on the diversity patterns of European aphyllophoroid fungi (cf. Abrego, Norberg, \& Ovaskainen, 2017).

\section{ACKNOWLEDGEMENTS}

We thank the colleagues who kindly shared their fungal data from different sites of Europe (Wolfgang Daemon, Masoomeh GhobadNejhad, Gro Gulden, Seppo Huhtinen, Yulia Khimich and Paul Kirk) as well as the thousands of researchers, conservation professionals and citizen scientists who collected the underlying data. We are grateful to Oleg Seliverstov and Anton Biatov for helping with the GIS analyses. We thank editors and two anonymous referees for the helpful comments on the manuscript. Work of $A O$ and EL was funded by the LOEWE excellence initiative of the state of Hesse (Germany) within the framework of the Cluster for Integrative Fungal Research (IPF); JHC was supported by the Aage V. Jensen Naturfond and the Danish National Research Foundation, grant no. DNRF96; SV was supported by the grant of the President of the Russian Federation (MK-6345.2015.4). NA was supported by the Research Council of Norway during the preparation of the manuscript (CoE grant no. 223257).

\section{ORCID}

Alexander Ordynets (iD http://orcid.org/0000-0002-2904-7094

\section{REFERENCES}

Abrego, N., Bässler, C., Christensen, M., \& Heilmann-Clausen, J. (2015) Implications of reserve size and forest connectivity for the conservation of wood-inhabiting fungi in Europe. Biological Conservation, 191, 469-477. https://doi.org/10.1016/j.biocon.2015.07.005

Abrego, N., Christensen, M., Bässler, C., Ainsworth, A. M., \& HeilmannClausen, J. (2017). Understanding the distribution of wood-inhabiting fungi in European beech reserves from species-specific habitat models. Fungal Ecology, 27, 168-174. https://doi.org/10.1016/j.funeco. 2016.07.006

Abrego, N., Norberg, A., \& Ovaskainen, O. (2017). Measuring and predicting the influence of traits on the assembly processes of wood-inhabiting fungi. Journal of Ecology, 105, 1070-1081. https://doi.org/10. 1111/1365-2745.12722

Andrew, C., Heegaard, E., Kirk, P. M., Bässler, C., Heilmann-Clausen, J., Krisai-Greilhuber, I., . . Kauserud, H. (2017). Big data integration: PanEuropean fungal species observations' assembly for addressing contemporary questions in ecology and global change biology. Fungal Biology Reviews, 31, 88-98. https://doi.org/10.1016/j.fbr.2017.01.001

Auger-Rozenberg, M.-A., Torres-Leguizamon, M., Courtin, C., Rossi, J.-P., \& Kerdelhué, C. (2015). Incongruent evolutionary histories of two parasitoids in the Mediterranean Basin: Influence of host specialization and ecological characteristics. Journal of Biogeography, 42, 1040 1051. https://doi.org/10.1111/jbi.12495

Barbosa, A. M., Brown, J. A., Jimenez-Valverde, A., \& Real, A. (2016). modEvA: Model evaluation and analysis. $\mathrm{R}$ package version 1.3.2. Retrieved from http://modeva.r-forge.r-project.org/

Baselga, A. (2010). Partitioning the turnover and nestedness components of beta diversity. Global Ecology and Biogeography, 19, 134-143. https://doi.org/10.1111/j.1466-8238.2009.00490.x

Baselga, A., \& Leprieur, F. (2015). Comparing methods to separate components of beta diversity. Methods in Ecology and Evolution, 6, 1069 1079. https://doi.org/10.1111/2041-210X.12388

Baselga, A., \& Orme, C. D. L. (2012). betapart: An R package for the study of beta diversity. Methods in Ecology and Evolution, 3, 808-812. https://doi.org/10.1111/j.2041-210X.2012.00224.x

Bässler, C., Müller, J., Dziock, F., \& Brandl, R. (2010). Effects of resource availability and climate on the diversity of wood-decaying fungi. Journal of Ecology, 98, 822-832. https://doi.org/10.1111/j.1365-2745. 2010.01669.x

Bernicchia, A., \& Gorjón, S. P. (2010). Corticiaceae s.l. Fungi Europaei No 12. Ed. Candusso, Italia.

Borcard, D., Gillet, F., \& Legendre, P. (2011). Numerical ecology with R. New York, NY: Springer. https://doi.org/10.1007/978-1-4419-7976-6

Brus, D. J., Hengeveld, G. M., Walvoort, D. J. J., Goedhart, P. W., Heidema, A. H., Nabuurs, G. J., \& Gunia, K. (2012). Statistical mapping of tree species over Europe. European Journal of Forest Research, 131, 145-157. https://doi.org/10.1007/s10342-011-0513-5

Collingridge, D. S. (2013). A primer on quantitized data analysis and permutation testing. Journal of Mixed Methods Research, 7, 81-97. https://doi.org/10.1177/1558689812454457

Cox, C. B., Moore, P. D., \& Ladle, R. (2016). Biogeography: An ecological and evolutionary approach. Chichester, UK: Wiley.

Dahlberg, A., Genney, D. R., \& Heilmann-Clausen, J. (2010). Developing a comprehensive strategy for fungal conservation in Europe: Current status and future needs. Fungal Ecology, 3, 50-64. https://doi.org/10. 1016/j.funeco.2009.10.004

Dapporto, L., Ramazzotti, M., Fattorini, S., Talavera, G., Vila, R., \& Dennis, R. L. H. (2013). Recluster: An unbiased clustering procedure for betadiversity turnover. Ecography, 36, 1070-1075. https://doi.org/10. 1111/j.1600-0587.2013.00444.x

Dyer, L. A., Singer, M. S., Lill, J. T., Stireman, J. O., Gentry, G. L., Marquis, R. J., ... Coley, P. D. (2007). Host specificity of Lepidoptera in tropical and temperate forests. Nature, 448, 696-699. https://doi.org/10. 1038 /nature05884

EAA. (2015). European environment agency, biogeographical regions, Europe 2015. Retrieved from http://www.eea.europa.eu/data-and-maps/ data/biogeographical-regions-europe-2 
Freijeiro, A., \& Baselga, A. (2016). Spatial and environmental correlates of species richness and turnover patterns in European cryptocephaline and chrysomeline beetles. ZooKeys, 597, 81-99.

Galante, T. E., Horton, T. R., \& Swaney, D. P. (2011). 95\% of basidiospores fall within $1 \mathrm{~m}$ of the cap: A field-and modeling-based study. Mycologia, 103, 1175-1183. https://doi.org/10.3852/10-388

Ghobad-Nejhad, M., Hallenberg, N., Hyvönen, J., \& Yurchenko, E. (2012). The Caucasian corticioid fungi: Level of endemism, similarity, and possible contribution to European fungal diversity. Fungal Diversity, 52, 35-48. https://doi.org/10.1007/s13225-011-0122-0

Gonzalez-Avila, P. A., Luna-Vega, I., Garcia-Sandoval, R., \& ContrerasMedina, R. (2016). Distributional patterns of the Order Gomphales (Fungi: Basidiomycota) in Mexico. Tropical Conservation Science, 9, 1940082916667140. https://doi.org/10.1177/1940082916667140

Halme, P., Heilmann-Clausen, J., Rämä, T., Kosonen, T., \& Kunttu, P. (2012). Monitoring fungal biodiversity - Towards an integrated approach. Fungal Ecology, 5, 750-758. https://doi.org/10.1016/j.fu neco.2012.05.005

Hattori, T. (2005). Diversity of wood-inhabiting polypores in temperate forests with different vegetation types in Japan. Fungal Diversity, 18, 73-88.

Hattori, T. (2017). Biogeography of polypores in Malesia, Southeast Asia. Mycoscience, 58, 1-13. https://doi.org/10.1016/j.myc.2016.09.004

Hawksworth, D., \& Lücking, R. (2017). Fungal diversity revisited: 2.2 to 3.8 million species. In J. Heitman, B. Howlett, P. Crous, E. Stukenbrock, T. James \& N. Gow (Eds.), The Fungal kingdom (pp. 79-95). Washington, DC: ASM Press.

Heikinheimo, H., Eronen, J. T., Sennikov, A., Preston, C. D., Oikarinen, E., Uotila, P., ... Fortelius, M. (2012). Convergence in the distribution patterns of Europe's plants and mammals is due to environmental forcing. Journal of Biogeography, 39, 1633-1644. https://doi.org/10. 1111/j.1365-2699.2012.02723.x

Heilmann-Clausen, J., Aude, E., van Dort, K., Christensen, M., Piltaver, A., Veerkamp, M., ... Òdor, P. (2014). Communities of wood-inhabiting bryophytes and fungi on dead beech logs in Europe - Reflecting substrate quality or shaped by climate and forest conditions? Journal of Biogeography, 41, 2269-2282. https://doi.org/10.1111/jbi.12388

Heilmann-Clausen, J., Maruyama, P. K., Bruun, H. H., Dimitrov, D., Læssøe, T., Frøslev, T. G., \& Dalsgaard, B. (2016). Citizen science data reveal ecological, historical and evolutionary factors shaping interactions between woody hosts and wood-inhabiting fungi. New Phytologist, 212, 1072-1082. https://doi.org/10.1111/nph.14194

Hijmans, R. J., Cameron, S. E., Parra, J. L., Jones, P. G., \& Jarvis, A. (2005). Very high resolution interpolated climate surfaces for global land areas. International Journal of Climatology, 25, 1965-1978. https://doi.org/10.1002/(ISSN)1097-0088

Hill, T., \& Lewicki, P. (2006). Statistics: Methods and applications. Tulsa, OK: Statsoft. https://doi.org/10.1016/B978-0-323-03707-5.50024-3

Hjortstam, K., Larsson, K.-H., Ryvarden, L., \& Eriksson, J. (1988). The corticiaceae of North Europe. Vol 1. Introduction and keys. Oslo: Fungiflora.

Holt, B. G., Lessard, J.-P., Borregaard, M. K., Fritz, S., Araújo, M. B., Dimitrov, D., ... Rahbek, C. (2013). An update of Wallace's zoogeographic regions of the world. Science, 339, 74-78. https://doi.org/10. $1126 /$ science. 1228282

Hortal, J. (2008). Uncertainty and the measurement of terrestrial biodiversity gradients. Journal of Biogeography, 35, 1335-1336. https://d oi.org/10.1111/j.1365-2699.2008.01955.x

Hortal, J., Diniz-Filho, J. A. F., Bini, L. M., Rodríguez, M. Á., Baselga, A., Nogués-Bravo, D., ... Lobo, J. M. (2011). Ice age climate, evolutionary constraints and diversity patterns of European dung beetles. Ecology Letters, 14, 741-748. https://doi.org/10.1111/j.1461-0248.2011. 01634.x

von Humboldt, A., \& Bonpland, A. (1805). Essai sur la géographie des plantes; accompagné d'un tableau physique des régions équinoxiales. Paris Levrault: Schoell et compagnie.
Keil, P., Schweiger, O., Kühn, I., Kunin, W. E., Kuussaari, M., Settele, J., ... Storch, D. (2012). Patterns of beta diversity in Europe: The role of climate, land cover and distance across scales. Journal of Biogeography, 39, 1473-1486. https://doi.org/10.1111/j.1365-2699.2012. 02701.x

Kotiranta, H., Saarenoksa, R., \& Kytövuori, I. (2009). Aphyllophoroid fungi of Finland. A check-list with ecology, distribution, and threat categories. Norrlinia, 19, 1-223.

Kreft, H., \& Jetz, W. (2010). A framework for delineating biogeographical regions based on species distributions. Journal of Biogeography, 37, 2029-2053. https://doi.org/10.1111/j.1365-2699.2010.02375.x

Legendre, P. (2014). Interpreting the replacement and richness difference components of beta diversity. Global Ecology and Biogeography, 23, 1324-1334. https://doi.org/10.1111/geb.12207

Linder, H. P., de Klerk, H. M., Born, J., Burgess, N. D., Fjeldså, J., \& Rahbek, C. (2012). The partitioning of Africa: Statistically defined biogeographical regions in sub-Saharan Africa. Journal of Biogeography, 39, 1189-1205. https://doi.org/10.1111/j.1365-2699.2012.02728.x

Lumbsch, T. H., Buchanan, P. K., May, T. W., \& Mueller, G. M. (2008). Phylogeography and biogeography of fungi. Mycological Research, 112, 423-424. https://doi.org/10.1016/j.mycres.2008.02.002

Magri, D., Vendramin, G. G., Comps, B., Dupanloup, I., Geburek, T., Gomory, D., ... de Beaulieu, J.-L. (2006). A new scenario for the Quaternary history of European beech populations: Palaeobotanical evidence and genetic consequences. New Phytologist, 171, 199-221. https://doi.org/10.1111/j.1469-8137.2006.01740.x

Mateo, R. G., Broennimann, O., Normand, S., Petitpierre, B., Araújo, M. B., Svenning, J.-C., ... Vanderpoorten, A. (2016). The mossy north: An inverse latitudinal diversity gradient in European bryophytes. Scientific Reports, 6, 25546. https://doi.org/10.1038/srep25546

Moncalvo, J. M., \& Buchanan, P. K. (2008). Molecular evidence for long distance dispersal across the Southern Hemisphere in the Ganoderma applanatum-australe species complex (Basidiomycota). Mycological Research, 112, 425-436. https://doi.org/10.1016/j.mycres.2007.12. 001

Mueller, G. M., Schmit, J. P., Leacock, P. R., Buyck, B., Cifuentes, J., Desjardin, D. E., ... Wu, Q. (2007). Global diversity and distribution of macrofungi. Biodiversity and Conservation, 16, 37-48. https://doi.org/ 10.1007/s10531-006-9108-8

Mukhin, V. (1993). Biota of xylotrophic Basidiomycetes of the West Siberian Plain. Ekaterinburg: UIF Nauka.

Müller, J., Brustel, H., Brin, A., Bussler, H., Bouget, C., Obermaier, E., ... Gossner, M. M. (2015). Increasing temperature may compensate for lower amounts of dead wood in driving richness of saproxylic beetles. Ecography, 38, 499-509. https://doi.org/10.1111/ecog.00908

Nieberding, C. M., \& Olivieri, I. (2007). Parasites: Proxies for host genealogy and ecology? Trends in Ecology \& Evolution, 22, 156-165. https://doi.org/10.1016/j.tree.2006.11.012

Nordén, J., Penttilä, R., Siitonen, J., Tomppo, E., \& Ovaskainen, O. (2013). Specialist species of wood-inhabiting fungi struggle while generalists thrive in fragmented boreal forests. Journal of Ecology, 101, 701-712. https://doi.org/10.1111/1365-2745.12085

Norros, V., Rannik, Ü., Hussein, T., Petäjä, T., Vesala, T., \& Ovaskainen, O. (2014). Do small spores disperse further than large spores? Ecology, 95, 1612-1621. https://doi.org/10.1890/13-0877.1

Oksanen, J., Blanchet, F., Kindt, R., Legendre, P., \& O'Hara, R. (2016). Vegan: Community ecology package. R package 2.3-3, Retrieved from https://cran.r-project.org/web/packa.

Peay, K. G., Bidartondo, M. I., \& Elizabeth Arnold, A. (2010). Not every fungus is everywhere: Scaling to the biogeography of fungal-plant interactions across roots, shoots and ecosystems. New Phytologist, 185, 878-882. https://doi.org/10.1111/j.1469-8137.2009.03158.x

R Core Team. (2016). R: A language and environment for statistical computing. Vienna, Austria: R Foundation for Statistical Computing. Retrieved from http://www.r-project.org/ 
Rämä, T., Nordén, J., Davey, M. L., Mathiassen, G. H., Spatafora, J. W., \& Kauserud, H. (2014). Fungi ahoy! Diversity on marine wooden substrata in the high North. Fungal Ecology, 8, 46-58. https://doi.org/10. 1016/j.funeco.2013.12.002

Ryvarden, L. (2015). Notes on basidiomycetes on driftwood in Finnmark, Norway. Synopsis Fungorum, 33, 50-52.

Ryvarden, L., \& Gilbertson, R. L. (1994). European polypores Vol. 1-2. Oslo: Fungiflora.

Ryvarden, L., \& Melo, I. (2014). Poroid Fungi of Europe (illustr. by T. Niemelä). Oslo: Fungiflora.

Sanderson, E. W., Jaiteh, M., Levy, M. A., Redford, K. H., Wannebo, A. V., \& Woolmer, G. (2002). The human footprint and the last of the wild. BioScience, 52, 891. https://doi.org/10.1641/0006-3568(2002)052 [0891:THFATL]2.0.CO;2

Sato, H., Tsujino, R., Kurita, K., Yokoyama, K., \& Agata, K. (2012). Modelling the global distribution of fungal species: New insights into microbial cosmopolitanism. Molecular Ecology, 21, 5599-5612. https://doi. org/10.1111/mec.12053

Shiryaev, A. G. (2014). Spatial differentiation of Russian clavarioid mycobiota: Ecological-geographical aspect. Russia: MV Lomonosov Moscow State University.

Simpson, G. G. (1943). Mammals and the nature of continents. American Journal of Science, 241, 1-31. https://doi.org/10.2475/ajs.241. 1.1

Sørensen, T. A. (1948). A method of establishing groups of equal amplitude in plant sociology based on similarity of species content, and its application to analyses of the vegetation on Danish commons. Kongelige Danske Videnskabernes Selskabs Biologiske Skrifter, 5, 1-34.

Stokland, J. N., Siitonen, J., \& Jonsson, B. G. (2012). Mortality factors and decay succession. In J. N. Stokland, J. Siitonen, B. G. Jonsson (Ed.), Biodiversity in Dead Wood (pp. 110-149). Cambridge: Cambridge University Press. https://doi.org/10.1017/CBO9781139025843

Svenning, J. C., Fløjgaard, C., \& Baselga, A. (2011). Climate, history and neutrality as drivers of mammal beta diversity in Europe: Insights from multiscale deconstruction. Journal of Animal Ecology, 80, 393402. https://doi.org/10.1111/j.1365-2656.2010.01771.x

Svenning, J.-C. C., Normand, S., \& Skov, F. (2008). Postglacial dispersal limitation of widespread forest plant species in nemoral Europe. Ecography, 31, 316-326. https://doi.org/10.1111/j.0906-7590.2008. 05206.x

Takhtajan, A. (1978). Floristic regions of the world. Leningrad: Nauka.

Tedersoo, L., Bahram, M., Polme, S., Koljalg, U., Yorou, N. S., Wijesundera, R., ... Abarenkov, K. (2014). Global diversity and geography of soil fungi. Science, 346, 1256688. https://doi.org/10.1126/science. 1256688

Tedersoo, L., \& Smith, M. E. (2013). Lineages of ectomycorrhizal fungi revisited: Foraging strategies and novel lineages revealed by sequences from belowground. Fungal Biology Reviews, 27, 83-99. https://doi.org/10.1016/j.fbr.2013.09.001

Treseder, K. K., Maltz, M. R., Hawkins, B. A., Fierer, N., Stajich, J. E., \& McGuire, K. L. (2014). Evolutionary histories of soil fungi are reflected in their large-scale biogeography. Ecology Letters, 17, 10861093. https://doi.org/10.1111/ele.12311

Triponez, Y., Arrigo, N., Espíndola, A., \& Alvarez, N. (2015). Decoupled post-glacial history in mutualistic plant-insect interactions: Insights from the yellow loosestrife (Lysimachia vulgaris) and its associated oil-collecting bees (Macropis europaea and M. fulvipes). Journal of Biogeography, 42, 630-640. https://doi.org/10.1111/jbi. 12456

Venables, W. N., \& Ripley, B. D. (2002). Modern Applied Statistics with S. New York, New York, NY: Springer. https://doi.org/10.1007/978-0387-21706-2

Wallace, A. R. (1876). The geographical distribution of animals. With a study of the relations of living and extinct faunas as eludicidating the past changes of the earth's surface. London: Macmillan and Co.

WCS \& CIESIN. (2005). Wildlife Conservation Society - WCS, and Center for International Earth Science Information Network - CIESIN Columbia University. Last of the Wild Project, Version 2, 2005 (LWP2): Global Human Footprint Dataset (Geographic). https://doi.org/10. 7927/h4m61h5f

Whittaker, R. J., Araújo, M. B., Jepson, P., Ladle, R. J., Watson, J. E. M., \& Willis, K. J. (2005). Conservation biogeography: Assessment and prospect. Diversity and Distributions, 11, 3-23. https://doi.org/10.1111/j. 1366-9516.2005.00143.x

\section{BIOSKETCH}

Alexander Ordynets is a $\mathrm{PhD}$ student at the Department of Ecology, University of Kassel. He is interested in the diversity, biogeography and taxonomy of aphyllophoroid fungi (non-gilled macroscopic Basidiomycota). Jacob Heilmann-Clausen, Claus Bässler and Nerea Abrego are the members of the international research group focused on diversity of wood-inhabiting fungi in the European beech forests (http://beechboys.eu/).

Author contributions: A.O. and J.H-C. conceived the idea; all coauthors collected the data; A.O., N.A., C.B. and A.S. analysed the data; A.O., J.H.-C and N.A. wrote the first draft of the manuscript, and all co-authors contributed to the writing.

\section{SUPPORTING INFORMATION}

Additional Supporting Information may be found online in the supporting information tab for this article.

How to cite this article: Ordynets A, Heilmann-Clausen J, Savchenko A, et al. Do plant-based biogeographical regions shape aphyllophoroid fungal communities in Europe? J Biogeogr. 2018;45:1182-1195. https://doi.org/10.1111/ jbi.13203 